\title{
Status and development trends of paste disposal technology with ultra- fine unclassified tailings in China
}

\author{
A-X. Wu University of Science and Technology Beijing, China \\ H-Z. Jiao University of Science and Technology Beijing, China \\ H-J. Wang University of Science and Technology Beijing, China \\ S-K. Yang University of Science and Technology Beijing, China \\ L. Li University of Science and Technology Beijing, China \\ Q-W. Yan Yunnan Chihong Zn and Ge Co., Ltd, China \\ H-J. Liu Inner Mongolia Mining Industry Co. Ltd, China National Gold Group, China
}

\begin{abstract}
Currently, China mostly deals with ultra-fine unclassified tailings using surface low-concentration discharge or underground backfilling. The former requires too much time for tailings slurry to consolidate, and creates poor stability for the tailings dam, and the latter has concentration problem, which can cause segregation. At the present time, China is trying to develop surface paste discharge and paste filling technologies.

The paper describes the evolution of surface paste disposal in China, analyses the application requirements and technical characteristics of surface paste disposal, and describes the progress of paste filling technologies in terms of tailings dewatering and thickening, mixing and preparation, and pipeline transport. Both the Wushan Copper Mine and Huize lead-zinc mine are typical of the mines in China to use relevant technology to deal with ultra-fine unclassified tailings. These mines have the largest scale of production and higher automisation respectively in surface paste disposal and paste filling, and achieve great application success.

The paper analyses the problems existing in the application of paste disposal technology with ultra-fine unclassified tailings in China, which mainly include the limitation of equipment manufacturing ability and high investment in the surface paste stacking and filling, and the key technology is developing. It puts forward the development trends of paste disposal technology, which will make breakthroughs in terms of basic theories and specific equipment for unclassified paste disposal, the spread of qualification to adopt paste disposal technology, and co-disposal technology of tailings and rock dumps.
\end{abstract}

\section{Introduction}

Incomplete statistics show that there are more than 1,500 tailings ponds in China (Zhang et al., 2005; Xie et al., 2008). Over 8 billion tonnes of tailings are stored on the surface, and increasing at a rate of 600 million tonnes (Mt) per year. At present, the quantity of tailings discharged each year are about $130 \mathrm{Mt}$ from iron mines, 140 Mt from non-ferrous metal mines, and 24.5 Mt from gold mines (Wang et al., 2010).

Currently, the ways of dealing with ultra-fine unclassified tailings in China are mostly surface stacking and underground filling. A common feature of these two methods is low solids concentration discharged. The concentration being low, tailings slurries are transported at a high velocity and cause pipe wear. Furthermore, once filled into the mining stope, the layers of tailings slurries can segregate due to high moisture content and long consolidation time. The result is that strength decreases, dewatering becomes difficult, and the water precipitated would also cause environmental pollution ( $\mathrm{Li}$ et al., 2009). Surface discharge of lowconcentration tailings slurries brings excess water, lengthens the consolidation time of tailings slurries, raises the phreatic line and increases the possibility of liquefaction, and consequently increases failure risk. In addition, low concentration surface discharge reduces the effective capacity and shortens the service life of the tailings pond (Sun et al., 2009). 
During long-term engineering practise, people have gradually realised the importance of improving the concentration of tailings slurries. Research on cemented filling techniques with high concentration and unclassified tailings has been conducted and widely popularised since the 1970s. During the 21st century, paste filling technology has been extensively applied. As for surface stacking, technological experiments of dry stacking were first conducted in gold mines, and currently, the paste disposal technology has come into a rapid development phase, becoming an energy-saving technique among mining enterprises.

\section{Status of unclassified tailings disposal technology in China}

\subsection{Surface direct discharge}

\subsubsection{Methods of tailings dam construction}

According to the different methods of dam construction, the tailings embankment could be divided into three types: upstream embankment, centreline embankment and downstream embankment (Blight and Bentel, 1983).

Due to the simple process, the upstream method is the most common method adopted all over the country. The characteristic of upstream dam construction is that the centreline of the dam constantly moves upstream of the starter dam, and the embankment is formed by the deposition effect of the flowing slurry. Upstream dam construction has poor stability due to low permeability and high phreatic surface. However, as the process is simple, the management convenient, and the operating cost low, upstream dam construction has been widely adopted at home and abroad (Rao, 2008).

In downstream dam construction, the embankment moves and rises in the downstream direction of the starter dam. Hydrocycloning is needed to separate the coarse and fine tailings. Here, the coarse particle fraction $(\mathrm{d}>0.074 \mathrm{~mm})$ should be more than $70 \%$. Because of the coarse particles, dam constructed by the downstream method have good stability, high shear strength, good permeability and a low phreatic surface. The main disadvantage of downstream construction is the requirement for a large quantity of coarse tailings for dam construction, so it is generally used where there is a large quantity of coarse tailings available or narrow topographic conditions (Gonzales, 2005). In addition, management is complex and the operating cost is high.

Centreline embankment construction is essentially an approach between upstream and downstream construction, where the dam body is raised vertically in the process of construction. The No. 4 tailings dam of Dexing copper mine adopted this method (Wei, 2004).

According to the survey of State Administration of Work Safety in 2008, among 4,054 investigated tailings ponds in metal mines, 3,689 mines adopt upstream embankment method, 136 mines adopt centreline embankment method, and 229 mines adopt downstream embankment method (Xie et al., 2009).

\subsubsection{Tailings pond hazards}

Currently, most metal mines in China choose a hydraulic conveying method to transport tailings slurry to the pond. This not only harms the surroundings greatly, and increases the security risk but also occupies creates a large footprint pond, and increases the capital and operating cost for the tailings pond, thus becoming the main problem restricting the sustainable development of metal mines (Lin and Zhang, 2006).

Traditional tailings discharge methods cause serious water loss. The solids concentration of the slurry is around $20-30 \%$, and therefore a large quantity of water reports to the pond, which will evaporate with time, or infiltrate and discharge to the surroundings. However, if the tailings' solids concentration is increased, the water loss would decrease sharply (Du et al., 2009).

Secondly, the tailings pond occupies a large space. At present, most tailings are just stacked on the surface rather than secondary utilisation. Based on a rough estimate, the area of tailings and mullock stacked in our country reached $18,700 \sim 24,700 \mathrm{~km}^{2}$ in 2000 , and increasing at a rate of $300 \sim 400 \mathrm{~km}^{2}$ per year, which takes up a lot of agricultural and forestry land (Wang and Guo, 2008). 
Low-concentration discharge seriously affects the ecological environment. The fugitive dust of the fine tailings, which contains harmful substances, causes atmospheric and environmental pollution. Taking the tailings of Jinchuan Nonferrous Metals Company as an example, the particles are fine and the tailings can be easily blown into the air, causing small-scale sandstorms and serious pollution (Luo, 2009). The water in the tailings often contains heavy metals and toxic admixtures, which will contaminate water and soil, and destroy the ecological balance.

The potential failure of a tailings dam will endanger the environment, people's lives and property. Currently, most tailings ponds in our country have exceeded the service life and capacity, causing serious effects on the stability and impermeability compared with the originally designed dam, therefore, dam failure and other disasters may happen (Qi, 2007). On 8 September 2008, a huge dam break occurred in Xiangfen County, Shanxi Province, which caused 276 deaths, bringing a very bad effect to the whole society.

\subsection{The status of mine backfilling}

\subsubsection{Status of classified tailings backfilling}

- Tailings classification: The filling materials must be dewatered in the stope to accelerate consolidation, so the argillaceous (clay) material must be removed, because it reduces permeability. The tailings finer than $37 \mu \mathrm{m}$ are removed by hydrocyclone, the underflow is called classified tailings (Cui et al., 2006).

- Classifying and thickening process: The thickening processes for unclassified tailings are generally divided into two types: the first is the hydrocyclone in series with a thickener, and the second is the hydrocyclone in series with a vertical tailings silo (Yuan et al., 2008; Geng, 2002). For the first method, tailings slurry is fed to the hydrocyclone after having been mixed by the mixing tank. The coarse tailings are in the underflow and the finer particles are in the overflow. The solids concentration of the underflow is up to $61 \%$ (Cui et al., 2007). For the second method, slurried tailings are pumped to a vertical tailings silo after classification by the hydrocyclone. The tailings are dewatered in the silo, with the underflow concentration around $65 \%$. A mud fluidisation system, installed at the bottom to the middle of the silo, can improve the uniformity of tailings (Cui et al., 1998).

- Problems: Classified tailings fill has resulted in two issues. Firstly, parts of the tailings produced during classification are not used for filling and tailings utilisation is low, and secondly, the fine tailings removed must still be disposed of in a tailings dam, which increases the technical difficulty and risk.

\subsubsection{Status of filling with cemented unclassified tailings}

- Concept: Filling with cemented unclassified tailings uses the unclassified tailings to fill the underground goaf. Therefore, it is suitable for the mines with a lack of filling materials or harmful substances contained in the tailings, and where a tailings pond cannot be built. There will be better perspective only when filling with high solids concentration.

- Process of filling with cemented unclassified tailings: It is necessary for this method to achieve high concentration to avoid slurry segregation. Otherwise, segregation will result in poor quality of fill, which results in difficulties in mining. In order to improve the concentration of slurry, it is common to use ordinary thickeners or vertical sand silos to dewater the slurry, which can produce concentrations by weight of $65-70 \%$. The unclassified tailings being measured (for solids concentration) is fed to a forced agitator or a horizontal agitator. Cement and other filling aggregates are added into the slurry to make the backfill, which is then transported underground for filling by piston pump (Zhang et al., 2004). The slump of backfill is usually $23-25 \mathrm{~cm}$. According to lab tests and theoretical analysis, when the slump is less than $22 \mathrm{~cm}$, the flow resistance of filling slurry is larger, and it is unable to achieve gravity transportation with small stowing gradient $(\mathrm{N}<2 \sim 3)$ (Liu et al., 2006). 
- Activation mixing of filling slurry: The main feature of filling with cemented unclassified tailings is that the tailings contain an excess of fines, which greatly increases surface area, constituting a standard dispersed, thixotropic system. It is difficult for conventional stirring methods to mix the fine particles with cement uniformly; therefore, an activation mixing process must be applied. After mixing by double screw agitator, the slurry is stirred by an activating agitator to produce high-class cemented fill (He et al., 2000; Zhang, 2000).

\section{New technology of ultra-fine unclassified tailings disposal}

\subsection{Surface paste disposal}

\subsubsection{Evolution of surface paste disposal}

Surface paste discharge technology evolved from dry stacking gold tailings, starting in the 1990s. According to the statistics, there are over 300 tailings facilities in China using the dry stacking technique. The main procedures of dry stacking are that tailings are filtered to around $20 \%$ moisture content and the filter cake is then transported to the disposal area by belt or truck. Compared to traditional wet discharge, dry stacking can reduce volume to be transported, increase the rate of water recovery and reduce safety incidents caused by dam failures. However, dry stacking also has shortcomings.

1) If the mine is not built on a greenfields site, technical modifications are required, at significant expense.

2) Tailings filtration is usually a one-off design, which cannot last longer than 5-10 years, and besides, the load distance and cost is increasing year by year.

3) Dry stacking technology does not gain obvious value for the mining with flotation process, except for gold tailings.

For these reasons this technology has not been widely adopted in China. Therefore, the technique of surface paste discharge has begun to be adopted (Xie et al., 2009).

\subsubsection{Surface paste disposal}

Both surface paste discharge and dry stacking belong to the category of high concentration discharge; the difference between them is the material being transported and deposited. As shown in Figure 1, tailings can be divided into two broad categories after dewatering: pumpable and unpumpable. Paste is obtained by further thickening of thickened tailings, and it can also be obtained by thickening from the original tailings slurry, which is in a state at which it can just be pumped. If dewatered by filter, the tailings will lose liquidity and cannot be pumped because of low moisture content (Luo, 2009). In this case, there is no choice but dry stacking.

Surface paste discharge can be employed in canyons, and in low-lying, flat or gently-sloping terrain conditions. The paste requires further desiccation and consolidation, since the paste still has appreciable moisture content before deposition. Therefore, paste discharge is more suitable for dry areas where there is a high evaporation capacity. Generally, the process of paste discharge includes three phases: paste preparation, paste transport and paste deposition.

Paste should be deposited by arranging the discharge points. The main layouts include down-valley scheme, perimeter scheme and centre scheme. A down-valley scheme is determined by the topographical conditions, and the paste is discharged from the top to the bottom. A perimeter scheme involves positioning the discharge points evenly around the perimeter, resulting in the deposit being a concave deposit. A centre scheme, as its name implies, involves positioning discharge points in the centre of the tailings area. Paste can be discharged through the top of the pipeline, and forms a conical stack. Compared to a perimeter scheme, a centre scheme can reduce the need for construction of perimeter berms, and the area occupied can also be smaller. Parameters of discharge points, including spacing, diameter and so on, play a certain role in the deposition. For example, the more even the discharge point layout, the thinner the thickness of each layer, the more efficient are evaporation and consolidation, leading to faster drying (Qi, 2007). 


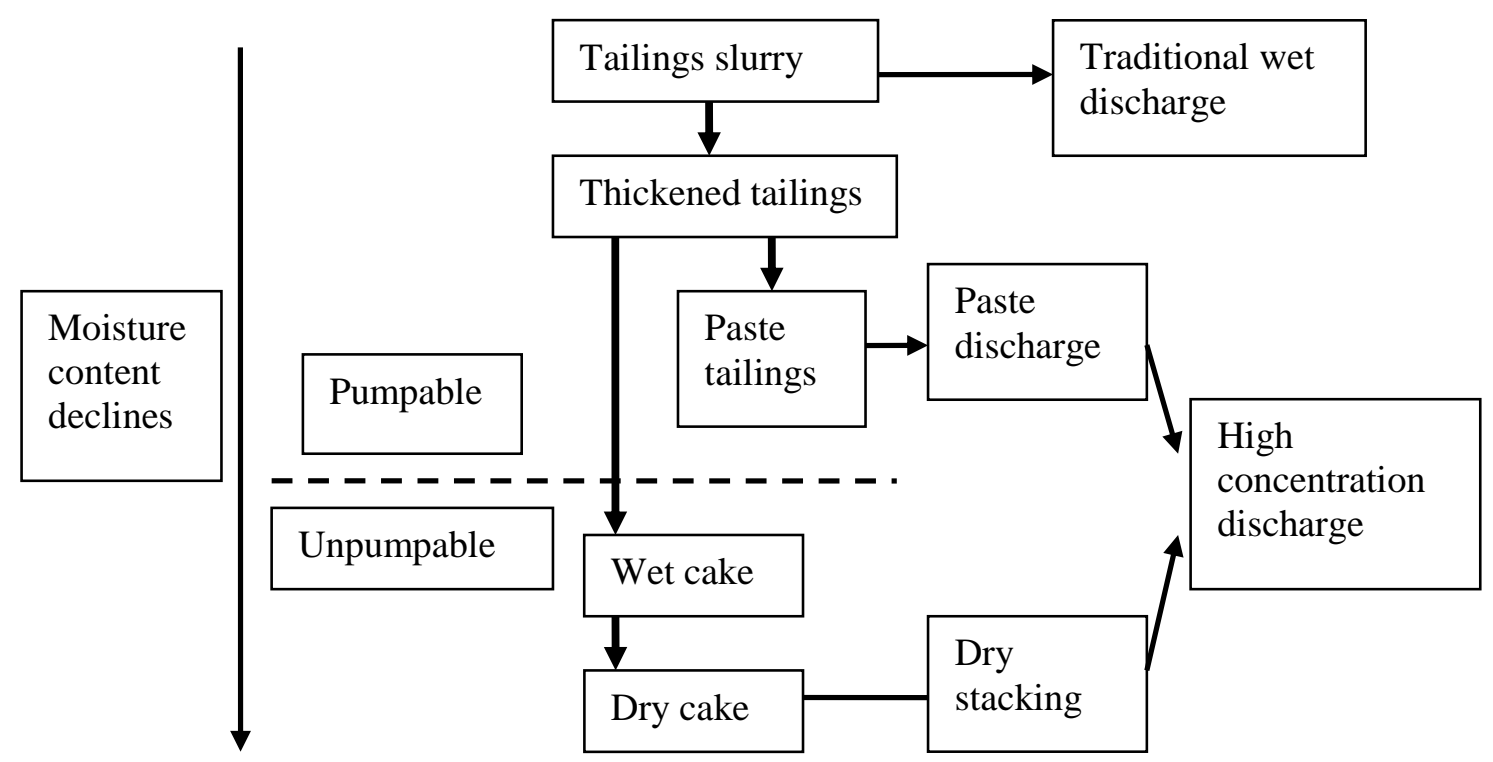

Figure 1 Diagram classifying tailings dewatering

When designing paste stacking system, the most important factors are the discharge concentration and the slope angle. Optimising the surface disposal scheme requires understanding the paste's rheological properties and the relevant operational parameters, as well as understanding how these properties and parameters can be modified.

\subsubsection{Characteristics of surface paste disposal}

Thickening the tailings slurry from the milling to achieve a non-segregating, non-dewatering, highconcentration (above 70\%) paste is the main technical feature of paste discharge. Paste is transported to the tailings area by gravity feed or pumping and is deposited in the pond in a certain layout. The moisture content of the paste can be minimised through evaporation and self-weight consolidation, thus increasing the dam stability. Compared to traditional direct discharge, paste discharge technology has superiority in terms of environmental protection, and saving reagent dosage; however the capital investment required is high (Fourie et al., 2001).

While inheriting the advantages of dry stacking, paste discharge has also overcome its limitations. Firstly, paste discharge can not only be applied in gold mines, but also other metal mines, even non-metal mines. Secondly, the stack formed by paste discharge has good stability, with long service life; it can also reduce the cost by allowing for long-distance pipeline transport. And lastly, with the fast development of deep cone thickeners in China and abroad, the dewatering devices available for paste discharge are much more reliable than those for dry stacking (Theriault et al., 2003).

Table 1 Contrast of paste stacking and direct discharge technology

\begin{tabular}{lll}
\hline & Paste Stacking Technology & Traditional Direct Discharge Technology \\
\hline Advantages & Environmental benefits & Low risk for established technology \\
& Water recovery & Low operating cost \\
& Residue metal recovery & Short construction period, earlier gain \\
& Low dosage of reagent & Low capital investment \\
Disadvantages & High capital investment & High risk of spills, endangering downstream residents \\
& & Harmful substance infiltration and groundwater pollution \\
& & Prone to dam collapses \\
& & Large area required \\
\hline
\end{tabular}




\subsection{Paste filling}

Paste filling is the process of making the optimum combination of one or more kinds of fill materials, to prepare a toothpaste-like cemented slurry with good stability, fluidity and plasticity, then transporting it to the goaf in plug flow under gravity or applied force (Liu et al., 2009). The characteristics of paste fill are non-segregating, non-bleeding and non-settling when transported.

There are usually three processes involved in preparing and transporting pastes: tailings dewatering and concentration, paste mixing and pipe transportation.

\subsubsection{Dewatering and concentration}

There are two main techniques used for dewatering and concentration in China. The first is the filtering process, where the concentration of filter cakes can reach $80-85 \%$ by weight, and the other involves the new deep cone thickeners, where the concentration of underflow can achieve $70-78 \%$ by weight (depending on mineralogy and operating conditions).

In the past, filters were used to dewater tailings for paste fill in China, because it was an effective and a simple process of dewatering. However, the concentration of filter cakes produced is too high, with low flow properties, so it is necessary to add a certain amount of water during material mixing to ensure the fluidity of the paste. Consequently, the cost is excessive because of the high energy consumption of the filter system, and frequent changes of the filter cloth ( $\mathrm{He}$ and $\mathrm{Gu}, 2008)$.

Nowadays, the new continuous thickeners are widely used in dewatering processes for tailings slurries, and it turns out that they can satisfy the requirements of paste preparation. The solids concentration of the underflow can reach over $77 \%$. After stirring and mixing of cement and aggregates, the solids concentration of the paste is $78 \%$ and its collapsed slump is $25-27 \mathrm{~cm}$ with good fluidity (Cui et al., 2007).

\subsubsection{The preparation of paste}

For the preparation of the paste with coarse aggregate, a two-stage horizontal mixing process was introduced. Multi-materials must be well agitated by two horizontal agitators in series, and then the paste can be made. The number of impellers in horizontal agitators is much more than in vertical agitators, and the shearing of the rotating blades is more direct. In addition, the rotational speed of the blades in horizontal agitators is slower, which reduces the requirements of torque and power, and avoids paste segregating by excessive stirring. The process of horizontal agitators in series is widely used, and the effect is remarkable for paste preparation with cement and dry coarse aggregates added (Zhou et al., 2007).

\subsubsection{The pipeline transportation of paste}

It is usual to pump the paste down to the underground stopes through pipelines. Due to the high concentration of paste, the pumps are piston pumps or diaphragm pumps. The pipelines are usually DN $150 \mathrm{~mm}$ high-strength steel tubes (Zhou and $\mathrm{Wu}, 2002$ ). When the fluidity is good, the paste can be transported through gravity; however, the precondition is that the potential energy of the paste must be higher than the friction in the pipeline.

\section{$4 \quad$ Project example}

\subsection{Huize lead-zinc mine, Chihong Co.}

The Huize lead-zinc mine is one of the largest special-rich poly-metallic mines in the world. The reserves are $2 \mathrm{Mt}$. The depth of the ore body is 700 1,200 m underground, while the lead-zinc grade is $25 \sim 30 \%$. The ore is also rich in silver, germanium, cadmium and other rare precious metals. It is a special high-grade ore in China (Liu et al., 2010).

\subsubsection{Application prerequisite}

The mine has accumulated more than $0.6 \mathrm{Mt}$ of mill tailings and more than $1 \mathrm{Mt}$ of lead smelting slag after decades of mining. In addition, the accumulated amount of the surface tailings and the slag is increasing at a 
rate of $0.25-0.3 \mathrm{Mt}$ per year. However, due to the current terrain limitations, the capacity of the tailings and slag area cannot be extended any more. Besides, the discharge and stockpiling of industrial waste are severely restricted, because the mine is located in the soil and water conservation and environmental protection area of the upper Yangtze River. Therefore, it is necessary to make good use of the surface tailings and the slag to fill the underground goafs. To this end, the mine constructed a paste filling system in 2006 based on a deep cone thickener.

\subsubsection{The basic properties of materials}

Table 2 shows that the specific surface area of unclassified tailings is almost two times that of the cement. The grain size of unclassified tailings is so superfine that cement has had difficulty to bind the unclassified tailings. As Figure 2 shows, the fine particle content $(<20 \mu \mathrm{m})$ in the paste slurry is over $57.95 \%$, while there are hardly any aggregates from 40 to $450 \mu \mathrm{m}$, so this aggregate is extremely gap-graded (Jiao et al., 2010).

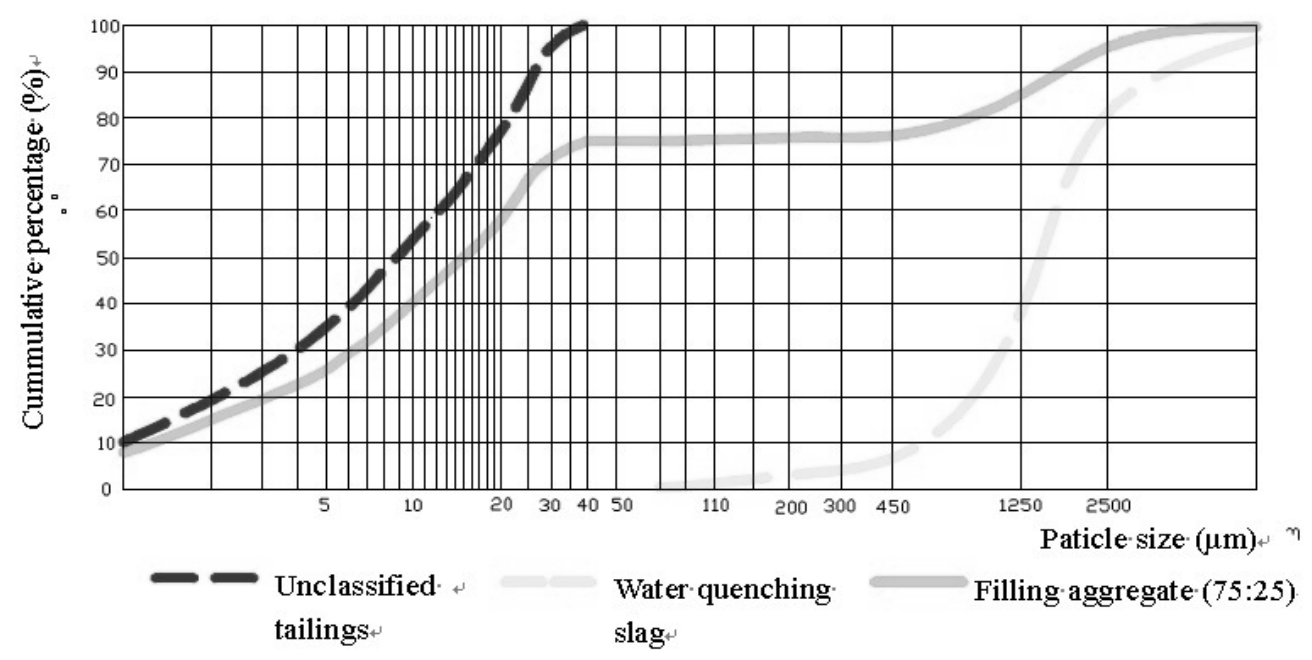

Figure 2 The particle size distribution of filling material

Table 2 Basic physical property parameters of the paste material

\begin{tabular}{lcccc}
\hline Item & $\begin{array}{c}\text { Specific } \\
\text { Gravity }\end{array}$ & $\begin{array}{c}\text { Bulk Density } \\
\left(\mathbf{t} / \mathbf{m}^{\mathbf{3}}\right)\end{array}$ & $\begin{array}{c}\text { Porosity } \\
(\mathbf{\%})\end{array}$ & $\begin{array}{c}\text { Specific Surface } \\
\text { Area }\left(\mathbf{m}^{\mathbf{2}} / \mathbf{m}^{\mathbf{3}}\right)\end{array}$ \\
\hline Cement & 3.1 & 1.3 & 58.06 & 582,000 \\
Unclassified tailings & 2.71 & 1.88 & 34.35 & 902,000 \\
Water quenching slag & 2.59 & 1.18 & 54.44 & \\
\hline
\end{tabular}

\subsubsection{Filling process}

As Figure 3 shows, the paste filling processes are: unclassified tailings from the processing plant are transferred directly into an $11 \mathrm{~m}$ diameter deep-cone thickener, and are then stirred uniformly. Then, the weight concentration of the tailings slurry reaches $76 \sim 78 \%$ after thickening. Smelting slag is transported through a disc feeder with belt scale measurement, while cement is transported through a double helix feeder with rush-board flow meter measurement. After that, the three materials enter together into an ATDIII- 9600 biaxial blade agitator and an ATDIII- $\varphi 700$ double helix mixing conveyor for secondary mixing to make paste with a concentration of 78 80\%. Finally, through the $150 \mathrm{~mm}$ diameter pipeline, they are pumped underground to fill the stope by a DHC-21180 twin piston pump produced by GEHO Co. (Wang et al., 2009).

The paste ratio is unclassified tailings: slag:cement $=7: 1: 1$. The 28 day unconfined compressive strength (UCS) is $3 \mathrm{MPa}$, and the filling direct cost is US\$11.50/ $\mathrm{m}^{3}$. The goaf is at a depth of $1,200 \mathrm{~m}$ and the pipeline length is $4.11 \mathrm{~km}$. In the case of pump maintenance, the paste is transported to the mining field with 
gravity, without pump pressure, and the stowing gradient can reach up to 3.41. In order to withstand the tremendous pressures exerted by the paste, the pipe wall thickness of the main line is $22 \mathrm{~mm}$, to resist the pressure of $20 \mathrm{MPa}$.

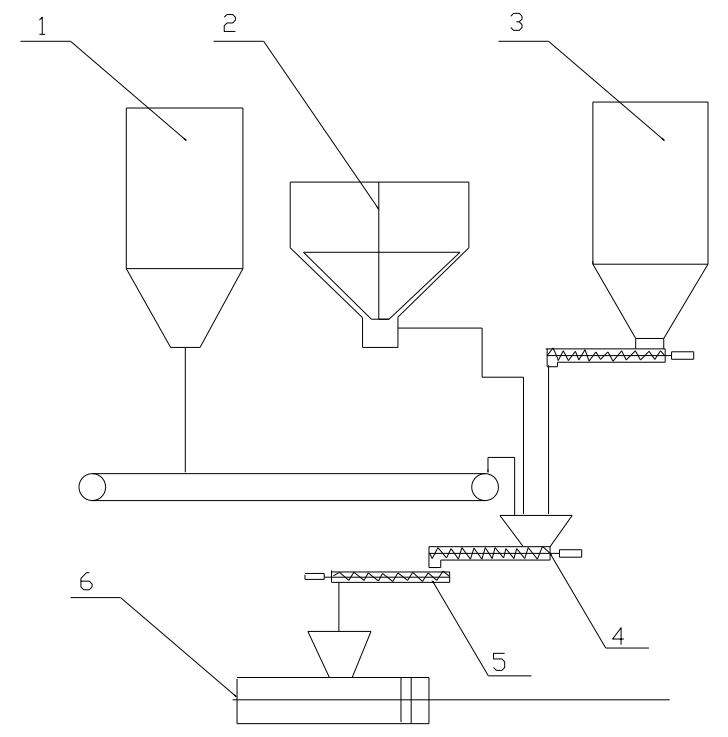

Figure 3 Schematic diagram of paste filling system in Chihong Co.: 1) smelting slag silo; 2) EIMCO deep-cone thickener; 3) cement silo; 4) dual-axis blade mixer; 5) dual-axis mixing screw conveyor; 6) DHC piston pump

\subsubsection{Effect of production practice}

The key for successful application of paste filling in the Huize Mine is that it has simplified the filling process. Actually, to introduce a deep-cone thickener for thickening and dewatering, to add dry cement directly to prepare paste on the surface, and to use paste with a slump of $20 \sim 25 \mathrm{~cm}$ as fill, can reduce the practical operational difficulties in the process of paste filling.

The paste filling concentration at the Huize Mine is $78 \sim 80 \%$, the maximum daily filling capacity is $1,264 \mathrm{~m}^{3}$, while the monthly capacity is $11,000 \mathrm{~m}^{3}$. To September 2010 , around $371,480 \mathrm{~m}^{3}$ of paste has been conveyed underground, with $441,232 \mathrm{t}$ of tailings consumed, which eases the storage capacity of tailings pond. The filled paste shortens the time of stope alternation, improves the stress state of the in situ rock, and purifies the underground working environment. At present, the mine's production is completely dependent on paste filling technology.

\subsection{The dry stacking technology in Wushan Copper Mine}

\subsubsection{Wushan Copper Mine}

Wushan Copper Mine, Neimeng, owned by Gold Group Corporation, China, is the fourth largest associated deposit in our country, with total metal reserve of $2.67 \mathrm{Mt}$. Its reserve is mainly copper and molybdenum, accompanied by a small amount of gold, silver and rhenium. Daily ore-processing capacity is 30,000 t, and high-concentration discharge is exploited for the tailings. Two sets of $40 \mathrm{~m}$ diameter deep-cone paste thickeners are used to thicken the tailings, which has an underflow concentration of $70 \sim 72 \%$ by weight.

\subsubsection{The basis of the dry stacking technology applied in Wushan Copper Mine}

The daily discharge of mine tailings has reached $39,398.8 \mathrm{t}$, with a weight concentration of $27.98 \%$. The mine is located on the Hulun Buir Grassland, where the ecology is fragile. Therefore, a discharge mode which has minimum impact on the environment had to be applied. The mine district is at high altitude, where annual average temperature is $-0.71{ }^{\circ} \mathrm{C}$ and lowest temperature is $-42.7^{\circ} \mathrm{C}$. Because of the frozen tailings ponds, the storage capacity would be reduced significantly if traditional wet discharge was adopted in such 
low temperature. The tailings dam is on grassland where rainfall is minimal, and there exists a lack of water for mine production. Therefore, in order to improve the efficiency of water utilisation and alleviate the water shortage, a discharge scheme with higher water efficiency had to be applied. Therefore, the mine introduced a paste process in 2007.

\subsubsection{The process of tailings dewatering, thickening and discharge}

As shown in Figure 4, the processes for Wushan copper paste dry stacking technology are as follows. Tailings slurry flows into the slurry tanks, where the slurry is pressurised by four pumps. Then the slurry is delivered through two ceramic-lined steel pipes into the two sets of $40 \mathrm{~m}$ diameter deep-cone thickeners, with a transportation distance of $1,800 \mathrm{~m}$. The tailings slurry is then mixed with flocculants deep inside the thickener for dewatering. When the weight concentration reaches $70-72 \%$, the slurry is discharged. Slurry discharged by the feeding pump is transported by seamless steel pipes into the storage pond for stacking, which is $2,000 \mathrm{~m}$ away. Flow meter and concentration meters are installed at the exit of the deep-cone thickeners to detect the quality of the slurry emitted.

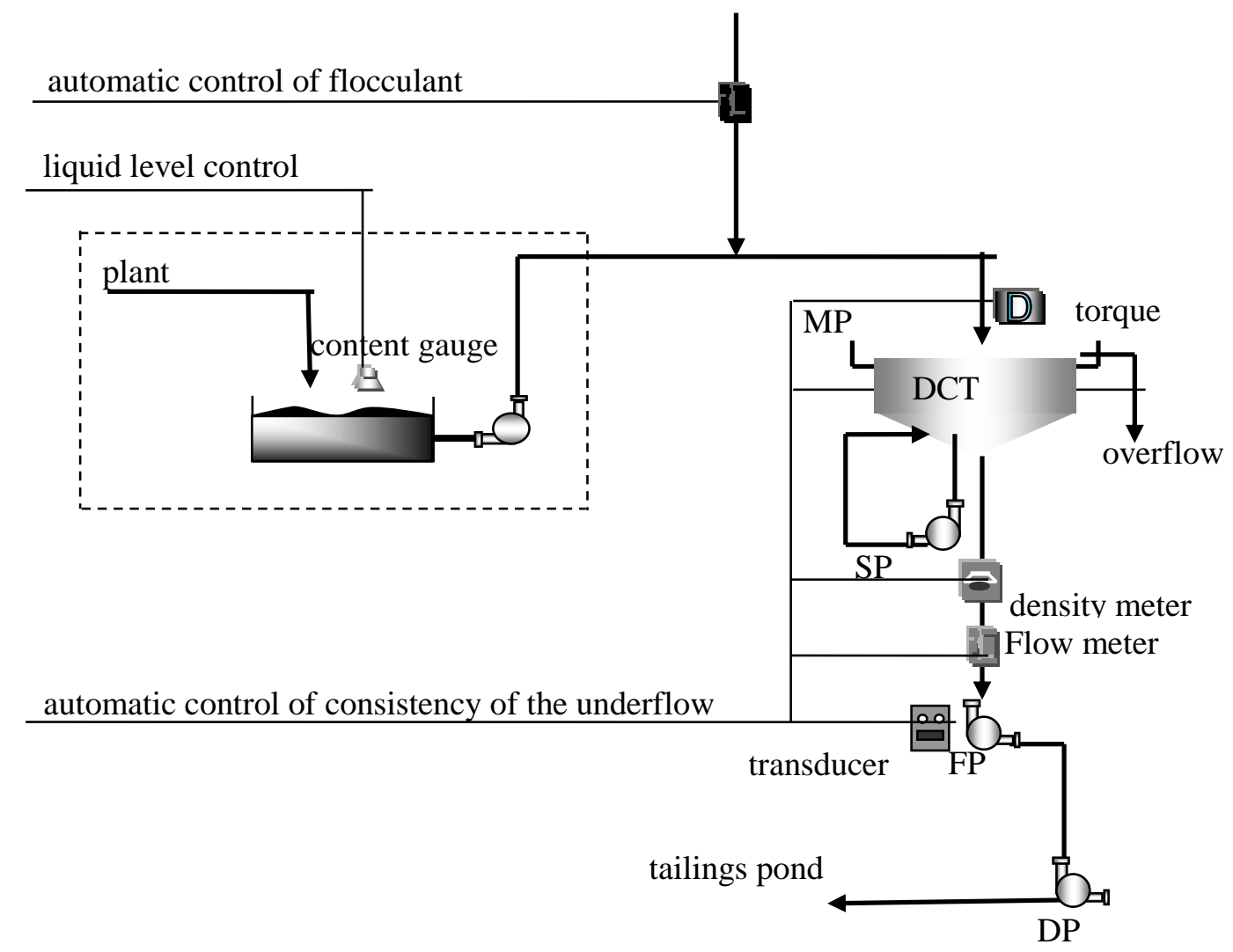

Figure 4 The process schematic of Wushan tailings thickening and paste stacking

\subsubsection{Discharge effects}

The paste with good flow properties can flow by gravity in the open channel which is constructed between the tailings discharge point and tailings pond, with no blockage occurring. The paste smoothly spreads to the border after entering the tailings area, increasing the exposed area, promoting water evaporation and accelerating the consolidation process, as shown in Figure 5. The stacking angle of paste in the reservoir is low, nearly horizontal. The effects of consolidation can be smooth and close and the tailings have high stability, as shown in Figure 6.

The maximum depth of freezing in the tailings can reach $3.89 \mathrm{~m}$ in winter, so the mine exploits underwater pumping to solve the freezing problems. Underwater pumping refers to pumping the paste below the ice surface in winter. This method has advantages as listed. 
- It can avoid the loss of flow property caused by freezing. When discharged underneath the ice, paste can flow freely, because there is enough space underneath the ice. If there is not enough space, the pressure caused by paste discharge would overall lift or partially damage the ice surface.

- It can avoid unrecoverable problem caused by paste freezing. If frozen, paste cannot be dewatered, thus water is unrecoverable.

- It can prevent dam damage from frost heaving. The enormous stress of the dam caused by frost heaving will damage the weak structures of the dam. If discharged underneath the ice, the water in the paste will not freeze, or damage the dam.

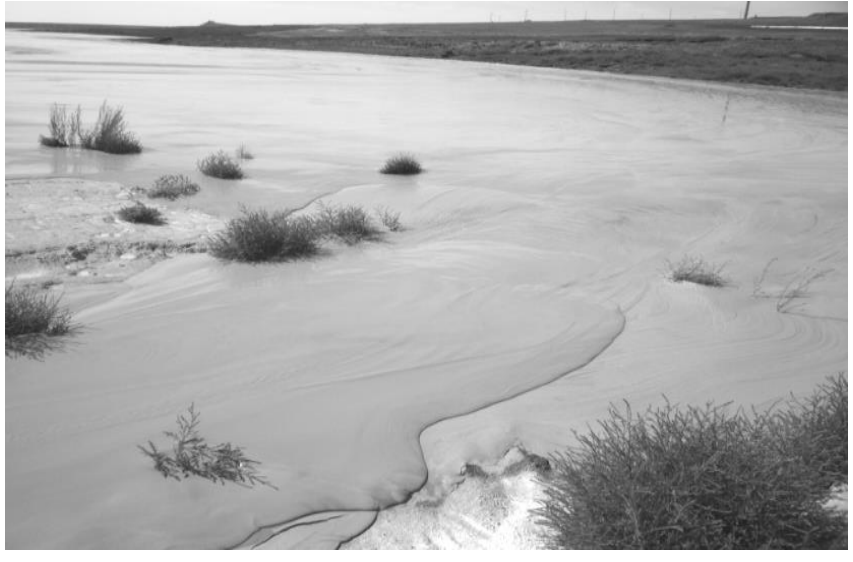

Figure 5 Paste flow in the tailings area

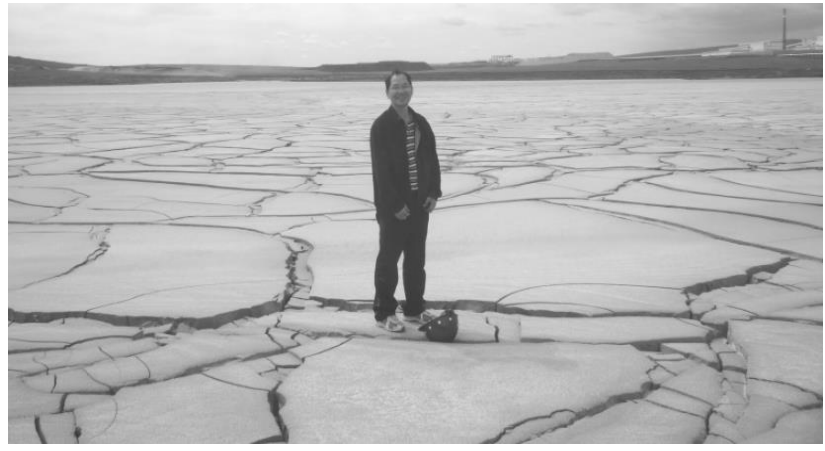

Figure 6 Effect of paste consolidation

\section{The development trends of ultra-fine unclassified tailings disposal}

\subsection{Problems}

Firstly, the manufacturing capability for paste production is low, and the results are not so good in China. The dewatering effect of the successive thickeners produced in China is poor and the concentration of underflow can be only $65 \%$. Therefore, the development of paste technology in our country is restricted.

Secondly, the level of technology for paste fill is low. From a technical perspective, some questions still have not been answered clearly. These problems include the following. What is paste? Different mines should adopt what proportion? How to improve the concentration of underflow? How to solve the partial abrasion of pipelines?

Thirdly, the technology of paste stacking in our country is in its infancy. The design process of paste stacking is unclear and some key parameters of paste stacking are still uncertain.

Fourthly, the investment required for paste technology is large. Generally, the construction of a paste system requires high capital investment, so it would be unacceptable for low profit and small-scale mines. 


\subsection{The development trends}

Tailings disposal is developing in a more economical, more secure, more environmentally-friendly direction. Given that paste disposal is a high-tech process, not only the rheological characteristics and theory of paste transport, but also the technical requirements of paste preparation, are unique. Therefore, in the early stages of this practice, there are undoubtedly some shortcomings; however, we should develop the technology in the direction as follows:

- Developing the basic theory of underground paste disposal for unclassified tailings: Firstly, the definition of paste should be interpreted theoretically or quantifiably. Paste flow should be of a plug form during transport, with no layering, no segregation and no bleeding occurring. However, it has not been determined how to use stratification degree, collapsed slump, bleeding rate and other parameters to describe paste quantitatively, according to different particle size distributions. Secondly, it is necessary to establish uniform systems and devices to obtain a suitable index test for paste. Currently, the indices and devices that used for paste testing are based on architectural mortar testing methods, but there are many differences in the grain sizes of aggregates between such mortars $(\mathrm{cm})$ and tailings paste $(\mathrm{mm})$. Thirdly, underground paste transport theory and paste gravitational flow theory should be developed further. With the increasing depth of mining and potential energy of paste, gravity feed will become the inevitable direction of development.

- Developing dedicated equipment for paste disposal: The dewatering devices used for paste filling are mainly thickeners in our country. Thickeners rely on gravity to achieve solid-liquid separation, and they are commonly used for ore dressing procedures or pre-treatment for material waiting to be filtrated. The feature of the device is continuous operation, while the filling process is discontinuous. The development of new types of thickeners, in order to adapt to the complex materials and changeable working conditions, is one of the development directions.

- Expanding applied range for tailings paste stacking technology: Given that paste stacking relies on natural evaporation to achieve consolidation, paste stacking becomes meaningless once precipitation is greater than evaporation. Wet inland regions can develop low strength of paste consolidation storage. Adding small amounts of cement material in paste can accelerate the consolidation process and prevent erosion by rain.

- Developing paste-waste rock co-disposal techniques in open pits: For an open pit mine, it is generally necessary to establish specialised rock dump, and the security and stability of the dump are significant problems. Due to the large void spaces that exist in the process of dumping waste rock, the permeability is good. Therefore, paste waste rock co-disposal techniques can be developed to put paste into the voids in the waste rock. In this way we can both save the establishment cost of the tailings facility, and enhance the stacking stability in the waste rock dump.

\section{Conclusion}

At present, the most common method of dealing with ultra-fine unclassified tailings is via low-concentration discharge to surface tailings ponds. Low concentration discharge can cause serious metal loss, take up a lot of land, cause environmental damage and also have serious potential safety problems. Unclassified tailings filling of mine voids can replace classified tailings filling and although this leads to improved utilisation rate of tailings, there are many deficiencies such as low strength of the initial fill body and the large dosage of cement required.

Surface paste stacking can solve the security and environmental problem of tailings dams, and has many benefits, but for technical and economic reasons it is a new technology in China. Paste filling can not only make use of the whole unclassified tailings, but also, with the material's concentration increasing to about $78 \%$ and the strength of the fill body increased to $3 \mathrm{MPa}$, this will increase the safety of mining activities.

Chihong's success in paste filling application is due to the simplification of the process. Adopting a deepcone thickener for one-stage thickening and dewatering, directly adding dry cement to make paste on the surface, and using gravity feed to transport paste, can reduce the practical operational difficulties of the paste filling process. Using paste discharge, Wushan Copper Mine has significantly reduced water consumption 
and improved capacity utilisation rate. It is an especially successful application of paste discharge in an alpine region, and will have a great relevance for similar mines.

For paste filling technology in China, we should develop the basic theory and dedicated devices for underground disposal with unclassified tailings. It is also necessary to expand the applied range of paste stacking to higher precipitation areas. In open pit mines, we can take the advantage of good permeability in waste stacking to develop open pit paste waste rock co-disposal techniques.

\section{References}

Blight, G.E. and Bentel, G.M. (1983) The behaviour of mine tailings during hydraulic deposition, Journal of the South African Institute of Mining and Metallurgy, Vol. 83, No. 4, pp. 73-86.

Cui, L., Wang, J.B., Sun, H.R. and Li, Y.H. (1998) Study on improving the density of discharged sand pulp from silo, Gold, Vol. 6, pp. 20-22.

Cui, X.Q., Lu, X.J. and Ge, H.C. (2006) Experimental study of classifying thickening of total tailings in a gold mine, Express Information of Ming Industry, Vol. 10(10), pp. 33-36.

Cui, X.Q., Lv, X.J., Ge, H.C. and Liu, L. (2007) Application classified thickening process in tailing dehydration of Beiminghe iron mine, China Mining Magazine, Vol. 16(2), pp. 73-76.

Du, T., Yun, B.J., Zhang, D.W. and Liu, Q.L. (2009) Discusses the harms and measures on safety management of tailings pond, Journal of Hebei Polytechnic University (Natural Science Edition), Vol. 5, pp. 9-12.

Fourie, A.B., Blight, G.E. and Papageorgious, G. (2001) Static liquefaction as a possible explanation for the Merriespruit tailings dam failure, Canadian Geotechnical Journal, Vol. 38, pp. 707-719.

Geng, M.X. (2002) The application of the system of hydraulic fill and consolidated fill with tails, Gold, Vol. 21(26), pp. 26-29.

Gonzales, V. (2005) Cobriza's Cu tailings surface stacking, in Proceedings Eighth International Seminar on Paste and Thickened Tailings (Paste05), R.J. Jewell and S. Barrera (eds), 20-22 April 2005, Santiago, Chile, Australian Centre for Geomechanics, Perth, pp. 261-274.

He, Z.X. and Gu, D.S. (2008) Development of research on hydraulic transport of mine filling in pipelines, Nonferrous Mines, Vol. 60(3), pp. 116-120.

He, Z.X., Xie, K.W., Zhang, C.Q. and Xie, C.J. (2000) Activating mixing technology and its application in mine backfill, Gold, Vol. 9, pp. 18-20.

Jiao, H.Z., Wang, H.J., Wu, A.X., Ji, X.W., Yan, Q.W. and Li, X. (2010) Rule and mechanism of flocculation sedimentation of unclassified tailings, Journal of University of Science and Technology Beijing, Vol. (6), p. 702.

Li, D.Q., Yang, C.X. and Shi, S.H. (2009) Research of the application of total tailing high density backfilling technology in deep underground mine, Metalmine, Vol. 7, pp. 13-16.

Lin, Y.S. and Zhang, W. (2006) Geohazard and risk assessment for tailing reservoir, Journal of Guilin University of Technology, Vol. 10, pp. 486-490.

Liu, X.H., Wu, A.X. and Wang, H.J. (2009) A primary discussion on the thickening law of paste-filling, Metal Mine, September, p. 38.

Liu, X.H., Wu, A.X. and Wang, C.L. (2010) Research on application of the microseismic monitoring system in Yunnan Huize Lead-Zinc Mine, Metal Mine, Vol. 1, pp. 35-37.

Liu, Y.B., Chen, J.Z. and Yang, Y.R. (2006) Numerical simulation of liquid-solid two-phase flow in slurry pipeline transportation, Journal of Zhejiang University (Engineering Science), Vol. 5, pp. 859-864.

Luo, M.J. (2009) A Discussion about dry storage of tailings, Journal of Nonferrous Metals Engineering and Research, Vol. 30(6), pp. 27-29.

Qi, H.L. (2007) A discussion on disposal methods of alumina red mud, Journal of Nonferrous Metals Engineering and Research, Vol. 28(23), pp. 121-125.

Rao, P.P. (2008) Research on the stability of the Plains Red Mud Tailings Dam in the Alumina Refinery of Ping Guo in Guangxi, Guangxi University, 6 p.

Sun, Y., Liu, H.F. and Liu, J.M. (2009) Current problems in the disposal of non-ferrous metallic tailings, Metal mine, Vol. 5, pp. 6-11.

Theriault, J.A., Frostiak, J. and Welch, D. (2003) Surface disposal of paste tailings at the Bulyanhulu Gold Mine, Tanzania, paper presented at Sudbury Mining and Environment Conference, Sudbury, Ontario, Canada.

Wang, H.J., Wu, A.X, Xiao, W.G., Zeng, P.H., Ji, X.W. and Yan, Q.W. (2009) The Progresses of Coarse Paste Fill Technology and its Existing Problem, Metal Mine, Vol. 401, pp. 1-5.

Wang, R., Zhang, J.R. and Dai, S.J. (2010) Utilization situation and development direction of non-ferrous metal mine tailings in China, Modern Mining, Vol. 6(6), pp. 6-9.

Wang, T. and Guo, Z.S. (2008) Discusses on the identification of dangerous harmful factors and safety management measures in tailings pond gold, Vol. 4, pp. 51-55.

Wei, Z.A. (2004) Research on the characteristics and dam stability of fine grained tailings, Chongqing University, 4 p. 
Xie, W., Sui, L.J. and He, Z.X. (2008) Current situation of tailings disposal technology and assumption, Express Information of Mining Industry, Vol. 5(5), pp. 10-12.

Xie, X.Y., Tian, W.Q., Wang, Y.H. and Zhang, X.K. (2009) The safety analysis of current situation and management countermeasure on tailing reservoir in China, Journal of Safety Science and Technology, Vol. 5(2), pp. 5-9.

Yuan, Z.G., Zhao, J. and Zhang, X.M. (2008) Application and practice of downward delamination cemented tailings filling stoping method in Daling Mine, Gold, Vol. 5(29), pp. 25-29.

Zhang, C.Q. (2000) Optimizing the structures and parameters of enforced activation agitators for highly concentrated cemented fill, Gold, Vol. 4, pp. 26-28.

Zhang, C.S., Wang, C. and F.Y. (2004) Study on restraining surficial mud on unclassified tailings filling body, Mining \& Metallurgy, Vol. 9, pp. 1-5.

Zhang, J.R., Xu, H. and Rao, J. (2005) Recycling economy and resourceful disposal of mine tailings, Multipurpose Utilization of Mineral Resource, Vol. 6, pp. 29-32.

Zhou, H.Q., Quan, Y.H., Zheng, B.C. and Zhao, C.Z. (2007) Proportioning of paste backfilling materials to moisture and its allowable measurement error, Journal of Mining and Safety Engineering, Vol. 24(3), pp. 270-274.

Zhou, B. and Wu, A.X. (2002) The development and application of no (low) waste mining technology in underground mines, Express Information of Mining Industry, May, pp. 1-3. 
